\title{
Investigation of QOL of hospice patients by using EORTC- QLQ-C30 questionnaire
}

\author{
Toshiko Tada1), Fumiko Hashimoto"), Yasuko Matsushita"), Yoshiyasu Terashima'2), \\ Tetsuya Tanioka'), Isao Nagamine ${ }^{1)}$, Hiroko Fujioka ${ }^{3)}$, and Nahoko Akiyama ${ }^{3)}$ \\ ${ }^{1)}$ Major in Nursing, School of Health Sciences, The University of Tokushima, Tokushima, Japan, ${ }^{2)}$ Department \\ of Digestive and Pediatric Surgery, Member of Palliative Care Team, The University of Tokushima \\ School of Medicine, Tokushima, Japan and ${ }^{3}$ Mitoyo Hospital, Kagawa, Japan
}

\begin{abstract}
This study was designed to investigate the quality of life (QOL) of cancer patients being cared for in a hospice, in the expectation that the results would serve as useful basic materials for improving the care of such patients. The subjects were 24 patients who had been diagnosed as having cancer and were hospitalized in the hospice wing of a hospital. The study was carried out as a crossing investigation using the Japanese version of the EORTC-QLQ-C30 Ver.3 questionnaire prepared by the European Organization for Research and Treatment of Cancer. The results of the survey showed that it was important to be prepared to prevent or treat diarrhea at the time of bowel movement and confirmed the need for care aimed at reducing fatigue. In addition, the emotional functioning and financial problems of the patients showed strong correlations with the QOL, revealing the need for psychological and financial support of cancer patients in hospices. J. Med. Invest. 51 : 125-131, February, 2004
\end{abstract}

Keywords : quality of life, hospice, cancer patients, EORTC-QLQ-C30 questionnaire

\section{INTRODUCTION}

Patient-centered medical care has long been advocated. However, there are many problems regarding the concrete measures for evaluating whether or not patient-based treatment is actually being provided $(1,2)$. Among them, it has been pointed out that it is necessary to elucidate how long-term treatment affects the quality of life (QOL) of cancer patients and to determine the timing and methods of providing care that will lead to maintenance or even improvement of the QOL of patients $(3,4)$. Moreover, Esper et al. indicate that the supportive care program (SCP) in cancer care contributes to continuity of care while being cost-effective (5). However, in the final stage of

Received for publication November 28, 2003 ; accepted January 7, 2004.

Address correspondence and reprint requests to Toshiko Tada, Major in Nursing, School of Health Sciences, The University of Tokushima, Kuramoto-cho, Tokushima 770-8509, Japan and Fax : +81-88-633-9033. life, the patient's condition becomes serious, and individual differences play a large role and the physical burden grows large. For these reasons, evaluation of the QOL can be difficult (6), and there are especially few reports regarding patients being cared for in hospices. In consideration of this background, the present questionnaire survey of the QOL of hospice patients was designed and carried out in the hope that it would generate useful basic materials for improving hospice care.

\section{METHODS}

\section{Subjects and methods}

The subjects were patients who had been diagnosed as having cancer and were hospitalized in the hospice wing of a major hospital. The questionnaire was returned by 27 patients. The QOL scale parameters had been completely responded to be 24 of those patients, and their responses were thus designated as effective 
responses and subjected to the data analysis. The 24 patients consisted of 8 women and 16 men. Their mean age was $62.5 \pm 10.5$ years, with a broad range of $42 \sim$ 89 years and a median age of 60.5 years. Sixteen of the 24 patients responded to the question regarding the time that had passed since diagnosis ; this parameter showed a broad range of one week to 108 months (9 years) and a mean duration of $7.8 \pm 26.7$ years. The mean duration of hospitalization was $1.6 \pm 1.3$ years.

This hospital where the subject is admitted is a local core hospital required to provide primary and tertiary care. The principles of care in the hospice ward are as follows : 1) medicine (providing good palliative care), 2) generality (providing palliative care as part of treatment for cancer. Providing terminal care to allow people to end their lives in their local community), 3) hospitality (providing comforting and soothing palliative care in which the values of patients are respected to the maximum degree). The nursing principles are to understand that patients and their families have their individual values, and to respect them in nursing. The nursing system is that fourteen nurses and 1 assistant nurse are assigned to 12 beds. Nursing is provided by a flexible two-shift system, in which 2 nurses are assigned to the night shift. The nursing system is fixed team nursing.

The study was carried out as a crossing investigation. The survey was conducted from September through November in 2002.

\section{Ethical considerations}

At first, the consent of this investigation execution obtained from the head of the nursing section. The investigation was carried out with the agreement of the subjects. A written explanation of the design of the survey was attached to the questionnaire, and the patients were informed that they were free not to participate. The subjects filled out the questionnaire in the hospice room. Receipt of the completed questionnaire was considered to represent informed consent.

\section{Contents of investigation}

Decision of the survey parameters was decided on the basis of giving top priority to minimizing the burden on the patients. As a result, the individual information requested was limited to the patient's gender, age, duration of hospitalization, type of treatment, mental attitude during hospitalization and the QOL evaluation parameters. The QOL evaluation parameters used in this study is the Japanese version of the EORTCQLQ-C30 Ver. 3 which consisted for 30 questions, dividing into 4 major scales: 1) Functioning, 2) 2 items of comprehensive QOL (state of health, quality of living), 3) 12 items of physical symptoms, and 4) financial difficulties.

The EORTC-QLQ-C30 Ver. 3 questionnaire scale used in this study is widely employed internationally and is considered to have a high degree of reliability (7-9). The Japanese version of the EORTC-QLQ-C30 Ver. 3 questionnaire prepared by the European Organization for Research and Treatment of Cancer was used as the QOL evaluation scale (10).

The comprehensive scale of QOL was represented by the question, "how good or bad was the quality of the general contents of your living and the state of your health during the past week?" and answers were given by checking on a scale from 1 ("very bad") to 7 ("very good"). The other questions, which concerned the state during the past week, were answered using a 4-point scale from "never"(1point) to "very often" (4 points).

Permission to use EORTC was obtained from Karen West (person who manages the original version) and Dr. Shimozuma (person who prepared the Japanese version) on the basis of the International Association Under Belgian Law (August, 1999).

\section{Analytical methods}

The scores of each scale were calculated according to the QOL Evaluation Manual (10).

For all scales, the Raw Score, RS, is the mean of the component items :

RS=Raw Score $=\left(I_{1}+I_{2}+\ldots .+I_{\mathrm{n}}\right) / \mathrm{n}$

Then for Functional scales :

$$
\text { Score }=\left\{1-\frac{(\mathrm{RS}-1)}{\text { Range }}\right\} \times 100
$$

And for Symptom scales/items and Global health status/QOL

$$
\text { Score }=\{(\mathrm{RS}-1) / \text { range }\} \times 100
$$

First, the mean scores of the Global health status/ QOL and each of the other scales were calculated and analyzed for correlations. Then, using the Global health status/QOL scale as the objective variable, multiple regression was performed using the other scales as explanatory variables (using the software Excel 2000 Ver. 5). Statistical significance of differences was defined as $\mathrm{p}<0.05$.

\section{RESULTS}

Table 1 compiles the mean values for each of the 
scales. The mean score for the Global health status/ QOL score was 44.1, and the standard deviation of 25.9 indicated large individual differences. Of the functional scale parameters, the cognitive functioning parameter showed the highest mean score, while the role functioning parameter had the lowest mean score. Of the physical symptom scale parameters, fatigue showed the highest score, while nausea $\cdot$ vomiting had the lowest score. The score for the financial difficulties scale was 51.4, which was higher than the mean score of the Global health status/QOL scale (Table 1).
Table 2 shows the results for the correlations between the Global health status/QOL score and the scores in the functioning scale. The highest correlations with the Global health status/QOL score were shown by the score for the cognitive functioning score parameter $(\mathrm{p}<0.01)$ and the score for the emotional functioning score parameter $(\mathrm{p}<0.01)$ in the functioning scale. In addition, the physical functioning score showed high correlations with each of the functioning scores, and those correlations were statistically significant. The score for the role functioning parame-

Table 1. The mean values for each of the scales

$(\mathrm{N}=24)$

\begin{tabular}{llcc}
\hline \multicolumn{1}{c}{ Scales } & \multicolumn{1}{c}{ Score } & Mean & S.D. \\
\hline Global health status/QOL & Global health status/QOL score & 44.1 & 25.9 \\
\hline Functional scales & Cognitive functioning score & 62.5 & 27.5 \\
& Social functioning score & 60.4 & 37.4 \\
& Physical functioning score & 59.7 & 26.3 \\
& Emotional functioning score & 59.0 & 30.7 \\
Symptom scales & Role functioning score & 38.2 & 36.9 \\
& Fatigue score & 53.7 & 33.4 \\
& Insomnia score & 48.6 & 35.4 \\
& Appetite loss score & 48.6 & 40.5 \\
& Pain score & 42.4 & 30.7 \\
& Constipation score & 26.4 & 31.1 \\
& Diarrhea score & 25.0 & 29.9 \\
& Dyspnoea score & 23.6 & 33.3 \\
\hline
\end{tabular}

Table 2. The correlations between the Global health status/QOL score and the scores in the functioning scale

$(\mathrm{N}=24)$

\begin{tabular}{|c|c|c|c|c|c|c|}
\hline Scales & $\begin{array}{l}\text { Global health } \\
\text { status/QOL } \\
\text { score }\end{array}$ & $\begin{array}{l}\text { Physical } \\
\text { functioning } \\
\text { score }\end{array}$ & $\begin{array}{l}\text { Role } \\
\text { functioning } \\
\text { score }\end{array}$ & $\begin{array}{l}\text { Cognitive } \\
\text { functioning } \\
\text { score }\end{array}$ & $\begin{array}{l}\text { Emotional } \\
\text { functioning } \\
\text { score }\end{array}$ & $\begin{array}{l}\text { Social } \\
\text { functioning } \\
\text { score }\end{array}$ \\
\hline $\begin{array}{l}\text { Global health } \\
\text { status/QOL score }\end{array}$ & 1.000 & & & & & \\
\hline $\begin{array}{l}\text { Physical } \\
\text { functioning score }\end{array}$ & 0.379 & 1.000 & & & & \\
\hline $\begin{array}{l}\text { Role functioning } \\
\text { score }\end{array}$ & 0.321 & ${ }^{* *} 0.652$ & 1.000 & & & \\
\hline $\begin{array}{l}\text { Cognitive } \\
\text { functioning score }\end{array}$ & $* * 0.557$ & ${ }^{* *} 0.613$ & $* * 0.664$ & 1.000 & & \\
\hline $\begin{array}{l}\text { Emotional } \\
\text { functioning score }\end{array}$ & $* * 0.726$ & $* 0.425$ & $* * 0.594$ & $* * 0.842$ & 1.000 & \\
\hline $\begin{array}{l}\text { Social functioning } \\
\text { score }\end{array}$ & 0.097 & $* * 0.548$ & 0.329 & 0.338 & 0.030 & 1.000 \\
\hline
\end{tabular}

${ }^{* *}: \mathrm{p}<0.001,{ }^{*}: \mathrm{p}<0.05$ 
ter showed high degrees of correlation $(\mathrm{p}<0.01)$ with the scores of both the cognitive functioning score parameter and the emotional functioning score parameter (Table 2).

Table 3 presents the results for the correlations between the Global health status/QOL score, the physical symptom scores and the financial difficulties score. Both the physical symptom score and the financial difficulties score showed a negative correlation with the Global health status/QOL score. The correlations for the parameters of fatigue, pain, insomnia, diarrhea and financial difficulties were all statistically significant. The score for fatigue showed a significant correlation with the scores of each of the other parameters in the physical symptom scale, except for the score for diarrhea. Financial difficulties score also showed a high degree of correlation with the Global health status/ QOL score $(\mathrm{p}<0.001)$ (Table 3$)$.

Table 3. The correlations between the Global health status/ QOL score and the physical symptom scores and the financial difficulties score

$(\mathrm{N}=24)$

\begin{tabular}{lc}
\hline \multicolumn{1}{c}{ Scales } & Correlation \\
\hline Fatigue score & $* *-0.557$ \\
Nausea and vomiting score & -0.295 \\
Pain score & $*-0.560$ \\
Dyspnoea score & -0.153 \\
Insomnia score & $*-0.450$ \\
Appetite loss score & -0.393 \\
Constipation score & -0.323 \\
Diarrhea score & $* *-0.455$ \\
\hline Financial difficulties score & $* *-0.556$ \\
\hline
\end{tabular}

Table 4 presents the results of the multiple regression analysis performed using the Global health status/ QOL score as the objective variable and the functioning score as the explanatory variable. The result of ANOVA showed statistical significance $(\mathrm{p}<0.01)$, with a high coefficient of multiple correlation of 0.783 . Within the functioning scale score, the score for the emotional functioning parameter showed a significant correlation $(p<0.01)$ with the Global health status/QOL score (Table 4).

Table 5 compiles the results of the multiple regression analysis performed using the Global health status/ QOL score as the objective variable and the physical symptom score and the financial difficulties score as the explanatory variable. The coefficients of multiple correlations were high, and the correlations between the variables were statistically significant $(p<0.01)$. When the physical symptom score served as the explanatory variable, the diarrhea parameter score showed statistical significance $(\mathrm{p}<0.01)$ with the Global health status/ QOL score (Table 5).

The questionnaire provided the patients to comment freely regarding their mental attitude during hospitalization. As a result, four patients made the following comments : "I do some walking in order to increase my appetite even a little bit" ; I am adjusting my diet" ; "I am trying to follow the instructions of the doctors and nurses" ; "I am trying to exercise as much as possible, such as by walking" ; and "I am planning for my second life after I am released from the hospital."

Table 4. The multiple regression analysis performed using the functioning score as the explanatory variable

\begin{tabular}{|c|c|c|c|c|}
\hline Functional scales & $\begin{array}{c}\text { Regression } \\
\text { coefficient }\end{array}$ & Standard error & $\begin{array}{l}\text { Standard } \\
\text { regression } \\
\text { coefficient }\end{array}$ & $\begin{array}{c}\text { Significant } \\
\text { level }\end{array}$ \\
\hline Physical functioning score & 0.253 & 0.224 & 0.257 & 0.273 \\
\hline Role functioning score & -0.212 & 0.155 & -0.301 & 0.188 \\
\hline Cognitive functioning score & -0.391 & 0.329 & -0.414 & 0.250 \\
\hline Emotional functioning score & 0.963 & 0.271 & 1.139 & 0.002 \\
\hline Social functioning score & 0.112 & 0.138 & 0.161 & 0.427 \\
\hline \multicolumn{5}{|c|}{ Multiple correlation coefficient $\mathrm{R}=0.783$} \\
\hline \multicolumn{5}{|c|}{ Coefficient of determination $\mathrm{R} 2=0.613$} \\
\hline \multicolumn{5}{|c|}{ Coefficient of determination (after correction for the degree of freedom) $=0.505$} \\
\hline \multicolumn{5}{|c|}{ Analysis of variance $:$ Unbiased variance $=1897.64, \mathrm{P}$ value $=0.00254$} \\
\hline The number of data $=24$ & & & & \\
\hline
\end{tabular}

The objective variable is the Global health status/QOL score and the explanatory variable is the functioning score. 
Table 5. the multiple regression analysis performed using the physical symptom scales and the financial difficulties scale as the explanatory variable

\begin{tabular}{|c|c|c|c|c|}
\hline & $\begin{array}{c}\text { Regression } \\
\text { coefficient }\end{array}$ & Standard error & $\begin{array}{l}\text { Standard } \\
\text { regression } \\
\text { coefficient }\end{array}$ & Pvalue \\
\hline Fatigue score & -0.554 & 0.378 & -0.712 & 0.164 \\
\hline Nausea and vomiting score & -0.419 & 0.393 & -0.321 & 0.305 \\
\hline Pain score & 0.355 & 0.388 & 0.419 & 0.376 \\
\hline Dyspnoea score & -0.063 & 0.188 & -0.081 & 0.741 \\
\hline Insomnia score & 0.083 & 0.266 & 0.113 & 0.760 \\
\hline Appetite loss score & 0.261 & 0.229 & 0.407 & 0.273 \\
\hline Constipation score & -0.053 & 0.166 & -0.063 & 0.756 \\
\hline Diarrhea score & -0.575 & 0.180 & -0.663 & 0.006 \\
\hline Financial difficulties score & -0.317 & 0.150 & -0.551 & 0.053 \\
\hline \multicolumn{5}{|c|}{ Multiple correlation coefficient $\mathrm{R}=0.829$} \\
\hline \multicolumn{5}{|c|}{ Coefficient of determination $\mathrm{R} 2=0.687$} \\
\hline \multicolumn{5}{|c|}{ Coefficient of determination (after correction for the degree of freedom) $=0.486$} \\
\hline \multicolumn{5}{|c|}{ Analysis of variance $:$ Unbiased variance $=1182.23, \quad P$ value $=0.020$} \\
\hline The number of data $=24$ & & & & \\
\hline
\end{tabular}

The objective variable is the Global health status/QOL scale and the explanatory variables are the physical symptom scales and the financial difficulties scale.

\section{DISCUSSION}

This survey of the QOL of patients in hospice care was carried out at only one institution and in only a small number of patients by using the EORTC-QLQ questionnaire scale. QOL is a subjective index of the patients. As a result, there has been much debate regarding the validity and reliability of the results of QOL surveys, and the difficulty of assessing the QOL has been pointed out (11-17). It is difficult to generalize on the basis of the results of the present study since the number of evaluated patients was small (4). Nevertheless, the following information was obtained from this QOL survey.

The emotional functioning of the patient can be surmised to exert a strong effect on his/her overall QOL. The present patients can be thought to have maintained their emotional functioning at quite a high level in view of the mean score for the emotional functioning and also the comments volunteered by a small number of patients.

Our survey did not investigate what sort of care was being provided in the hospital with the objective of maintaining the emotional functioning of the patients or the informal support system, such as the family, etc., which is also known to be important (18). For these reasons, we cannot comment with regard to the relationship between the results and the background setting.
However, evaluation of the QOL of cancer patients being cared for in a hospice in the final stage of their life can be thought to be important for generating basic data that will lead to improved care (19-21). Hill described that the measurement of QOL was used in developing patient-care plans and to identify differences in QOL assessment between nurse and patient as an aid to reflective practice (22). The results of our present study revealed that the emotional functioning of the patient in a hospice institutional environment having little connection with society at large showed strong correlations with the physical functioning and the conscious and role functioning. These findings indicate the importance of care directed at maintaining the emotional and psychological health of hospice patients.

With regard to the physical aspects of the patients, symptoms of fatigue and diarrhea showed high degrees of correlation with the Global health status/QOL, and especially diarrhea was confirmed to show a relationship with the Global health status/QOL on the basis of the results of multiple regression analysis. The preceding literature showed that constipation intensity was related to QOL $(23,24)$. But, diarrhea contributes to dissipation of the energy of patients and is thought to be a cause of fatigue. Accordingly, it can be surmised that for the care of terminal cancer patients it is important to be prepared to prevent or treat diarrhea at the time of bowel movement. Because the present 
QOL questionnaire parameters do not include the name of the disease, the pathological status or the details of the care provided, no discussion can be made regarding the relationships of these parameters with the burden being placed on the patients. However, the importance of being cared for diarrhea and providing care aimed at alleviating fatigue has been confirmed in this regard. Accordingly, a policy of being cared for diarrhea and alleviating the fatigue of patients will serve as a good approach to hospice care. In addition, the results of this study confirmed once again the strong relationship of financial difficulties to a poor QOL of the patient. The fact that financial difficulty is a serious problem for patients in the terminal stage of life has already been pointed out by others (25), and our present results support that earlier finding. Thus, support for the financial problem of hospice patients also cannot be neglected.

A survey of the QOL of patients in hospice care was carried out using the EORTC-QOL questionnaire scale, although it was performed at only one institution and in only a small number of patients. The results showed the importance of care aimed at supporting the emotional aspects of patients and reducing their level of fatigue. It was surmised that one concrete step for achieving these goals is being care for diarrhea.

In the future, we hope to develop a guideline for the support of terminal-care hospice patients on the basis of learning from the patients themselves regarding their individual feelings and wishes, not relying merely on the results of a questionnaire.

We think that it is necessary to investigate to more subjects and to generalize of the data.

\section{ACKNOWLEDGMENTS}

The authors express their deep gratitude to the various people who cooperated on the execution of this survey. The present study was supported in part by a scientific research grant from the Ministry of Education, Culture, Sports, Science and Technology (Grant No. 13672459).

The part of this research was announced orality in Research meeting of QOL in Tokyo (September, 2003).

\section{REFERENCES}

1. The society for the study of Quality of Life edition : Quality of Life-As for the expensive medi- cal treatment of QOL, Nissouken,Tokyo, 1999, pp.9-17 (in Japanese)

2. Adati $\mathrm{H}$ : Research on Quality of Life (QOL) of the chronic disease patient (1). Bulletin of Gifu university medical technological junior college 5 (in Japanese) : 143-151, 1999

3. Urushizaki I, Kurihara M tr. (Kuchler, T) : Quality of Life and Health (Urushizaki I tr. : The ninth chapter QOL research in the cancer, QOL-From that general idea, to the application). Shupuringa Fealak, Tokyo, First edition, 1996, pp.115-127 (in Japanese)

4. Cohen SR, Boston P, Mount BM, Porterfield P: Changes in quality of life following admission to palliative care units. Palliat Med $15: 363-71$, 2001

5. Esper P, Hampton JN, Finn J, Smith DC, Regiani $\mathrm{S}$, Pienta KJ : A new concept : the supportive care program, Am J Hosp Palliat Care. Nov-Dec 16 : 713-22, 1999

6. Yamamoto M, Yagi Y, Hujita H, Minami Y, Hukushima T, Matsushima T, Mandai T: Method with the QOL evaluation in the terminal medical care, Quality of Life Journal 4 (in Japanese) :6975, 2003

7. Apolone G, Filiberti A, Cifani S, Ruggiata R, Mosconi P: Evaluation of the EORTC QLQ-C30 questionnaire : a comparison with SF-36 Health Survey in a cohort of Italian long-survival cancer patients. Ann Oncol 9 : 549-557, 1998

8. Fukushima T:Terminal medical treatment and QOL : The manual of the QOL evaluation (editorial supervision by Mandai T). First Edition. Inter Medica, Tokyo, 2001, pp.180-185 (in Japanese)

9. Kondo H, Shirao K: The research of QOL in the clinical oncology, Kanwa Iryogaku 2 (in Japanese): 9-14, 2000

10. Fayers P, Aaronson N, Bjordal K, Curran D, Groenvold M : EROTC QLQ-C30 Scoring Manual. Second edition, Quality of Life Unit, EORTC Data Center, Brussels, 1999, pp.1-15

11. Aaronson NK : The European Organization for Research and Treatment of Cancer (EORTC) Modular Approach to Quality of Assessment in Oncology. Pan-Pacific Conference of ISOQOL Program \& Abstracts : 47, 2001

12. Kobayashi K,Takeda $\mathrm{H}$ : Japanese version of EORTC QLQ-C 30.Guideline for investigation and evaluation of QOL : Actual investigation and analytical procedures and the use of the results in bedside care (editorial supervision by Urushihara I). First Edition. Gan to Kagakuryouhou 
Sha, Tokyo, 1995, pp.11-15 (in Japanese)

13. Kobayashi $\mathrm{K}$ : The QOL questionnaire developed in the Japanese. Kanwa Iryougaku 2 (in Japanese) : 22-28, 2000

14. Kayaba $\mathrm{K}$ : The practice of the evaluation of QOL questionnaire. Karada no Kagaku 188 (in Japanese) : 20-23, 1996

15. Fukuhara $\mathrm{S}$ : Why is QOL important now?. In : Ikegami N, Fukuhara S, Shimozuma K, Ikeda S, eds. Its definition as a patient-oriented measure of outcome. Handbook for clinical assessment of QOL questionnaire, First edition. Igakushoin, Tokyo, 2001, pp.2-7 (in Japanese)

16. Shimozuma $\mathrm{K}:$ A peculiar measure due to the disease-Cancer. In : Ikegami N, Fukuhara S, Shimozuma K, Ikeda S, eds. A QOL evaluation handbook for the clinician, First edition. Igakushoin, Tokyo, 2001, pp.52-61 (in Japanese)

17. Shimozuma $\mathrm{K}$ : The typical evaluation method of QOL questionnaire of the foreign countries in the clinical tumor study,Kanwa Iryougaku 2 (in Japanese) : 29-33, 2000

18. Higashi K., Nagata C.: Characteristics of family coping with home-terminal care and nursing interventions, Journal of Japan Academy of Community Health Nursing 6 (in Japanese) : 40-48, 2003
19. Hill $\mathrm{N}$ : Use of quality-of-life scores in care planning in a hospice setting : the theme of revelation. Int J Palliat Nurs 8 : 591-3, 2002

20. Rummans T A, Bostwick JM, Clark MM ; Maintaining quality of life at the end of life. Mayo Clin Proc 75 : 1305-10, 2000

21. Horton R:Differences in assessment of symptoms and quality of life between patients with advanced cancer and their specialist palliative care nurses in a home care setting. Palliat Med 16 : 488-94, 2002

22. Hill N. : Use of quality-of-life scores in care planning in a hospice setting:a comparative study. Int J Palliat Nurs 8 : 540-7, 2002

23. McMillan SC, Small BJ : Symptom distress and quality of life in patients with cancer newly admitted to hospice home care, Oncol Nurs Forum $29: 1421-8,2002$

24. McMillan SC, Weitzner M : How problematic are various aspects of quality of life in patients with cancer at the end of life? Oncol Nurs Forum $27: 817-23,2000$

25. Tanaka A, Iwamoto T, Kaneyasu H, Petrini MA: Thoughts and feelings of in-patients with advanced terminal cancer: Implications for terminal care improvement. Nursing and Health Sciences 1 : 189-194, 1999 